УДК 629.423.31

\title{
ЗАСТОСУВАННЯ НЕЙРОКОНТРОЛЕРА ЯК ЕЛЕМЕНТА СИСТЕМИ КЕРУВАННЯ АСИНХРОННИМ ТЯГОВИМ ДВИГУНОМ
}

Д.В. Павелко, канд. техн. наук С.Г. Буряковський

\section{ПРИМЕНЕНИЕ НЕЙРОКОНТРОЛЛЕРА КАК ЭЛЕМЕНТА СИСТЕМЫ УПРАВЛЕНИЯ АСИНХРОННЫМИ ТЯГОВЫХ ДВИГАТЕЛЕЙ}

\author{
Д.В. Павелко, канд. техн. наук С.Г. Буряковский
}

\section{APPLICATION NEUROCONTROLLER AS ELEMENTS CONTROL SYSTEM ASYNCHRONOUS TRACTION MOTORS}

\author{
D.V. Pavelko, cand. of techn. sciences S.G. Buryakovskyy
}

В даний час стає актуальним застосовувати нейроконтролери в системах керування асинхронними тяговими двигунами, щуо спеціалізуються на нейронних мережах. При модернізачії тягового рухомого складу є необхідність у швидкодії процесів для керування асинхронними двигунами. Дані системи керування на нейроконтролерах підтримують стабільну роботу асинхронних двигунів і рухомого складу в ичілому.

Ключові слова: нейроконтролер, нейронна мережа, програмне забезпечення, двійковий файл, перехідний прочес.

В настоящее время становится актуально применять нейроконтроллеры в системах управления асинхронными тяговыми двигателями, специализирующиеся на нейронных сетях. При модернизации тягового подвижного состава есть необходимость в быстродействии процессов для управления асинхронными двигателями. Данные системы управления на нейроконтроллерах поддерживают стабильную работу асинхронных двигателей $u$ подвижного состава в целом.

Ключевые слова: нейроконтроллер, нейронная сеть, программное обеспечение, двоччный файл, переходныий процесс.

Currently neurocontroller is actually applied in the control of asynchronous traction motors, specializing in neural networks. When upgrading traction rolling stock is a need for processes to speed control of asynchronous motors. The data management system to support the neurocontroller stable operation of induction motors and rolling stock in general.

Keywords: neurocontroller, neural network software, binary; transition process.

Останніми десятиліттями у світі бурхливо розвивається нова прикладна галузь математики, що спеціалізується на штучних нейронних мережах (HM). Актуальність досліджень у цьому напрямі підтверджується масою різних застосувань HM. Це автоматизація процесів розпізнавання образів, адаптивне управління, апроксимація функціоналів, прогнозування, створення експертних систем, організація асоціативної пам'яті i багато інших застосувань.

Хоча існуючі методи синтезу систем автоматичного управління електроприводами, як, наприклад, модальне управління, дозволяють створювати 
системи $з$ достатньо високими показниками регулювання, їх практична реалізація пов'язана 3 технічними труднощами. Цілком природна ідея замінити використовувані лінійні регулятори нелінійними, які при меншому числі сигналів від вимірюваних координат забезпечували б необхідну вихідну дію, що управляла, для об'єкта регулювання. Таку можливість забезпечує нелінійний регулятор, що реалізовується у вигляді нейроконтролера, який $\epsilon$ нейронною мережею, що функціонує за принципом біологічних нейронних мереж.

На рис. 1 показана схема використання нейроконтролера для управління об'єктом по командах $U_{3}(k), \mathrm{y}$ дискретні моменти часу.

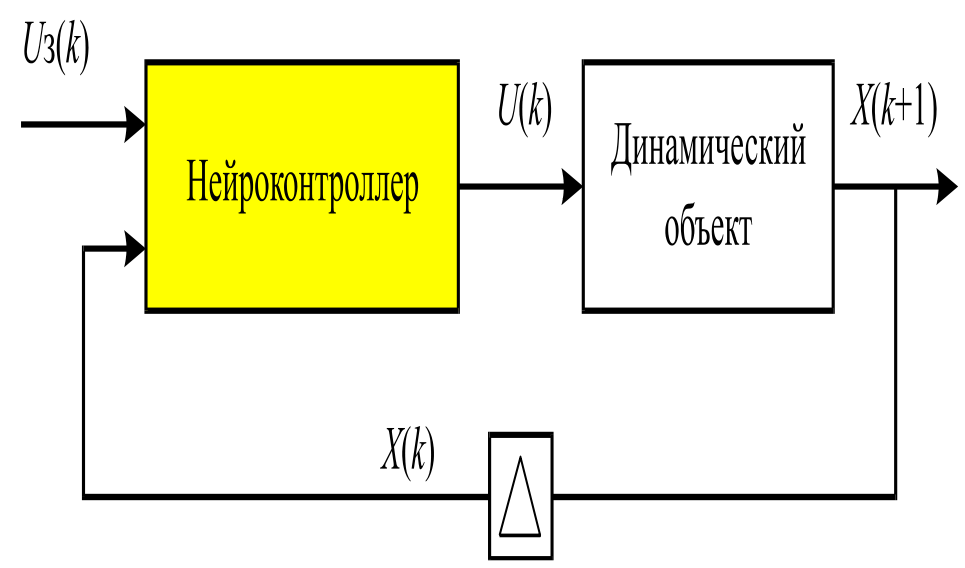

Рис. 1. Управління об'єктом за допомогою нейроконтролера

Мета навчання - додання нейроконтролеру здатності виробляти послідовність дій $U(k)$, які управляють, що переводить об'єкт з довільного початкового стану в заданий кінцевий стан за кінцеве число кроків. Алгоритм зворотного розповсюдження помилки цілком придатний для цієї мети, але він вимагає інформації про помилку на вихідному шарі IHM.

Для синтезу нейроконтролера використовується таке програмне забезпечення:

- Borland Delpfi 7.0 для розрахунку системи диференціальних та алгебраїчних рівнянь, що описує асинхронну машину i створення на базі цього розв'язання dllбібліотеки, в якій містяться дані щодо безпосередньо самого розв'язку, критерію похибки та параметрів нейтронної мережі.
- Mendel 4 для розрахунку вагових коефіцієнтів нейронів методом генетичного алгоритму, що записуються до файла звіту у форматі INI.

- RepToMfile для конвертування файла звіту з формату INI до формату mat.

- Matlab 6.5 для моделювання нейроконтролера та зв'язку його $з$ моделлю асинхронного двигуна.

Програма для спрощення користування розбита на декілька модулей. Кожен 3 них виконує одну чи декілька функцій. Основним $\epsilon$ модуль «Lokomotiv.dpr». В ньому задана кількість нейронів вхідного, прихованого та вихідного шару, що обробляє інформацію від приєднаних блоків «DeCodeParam.» «Globals» та «TestSystem» і готує iï для обробки в «Mendel 4». 


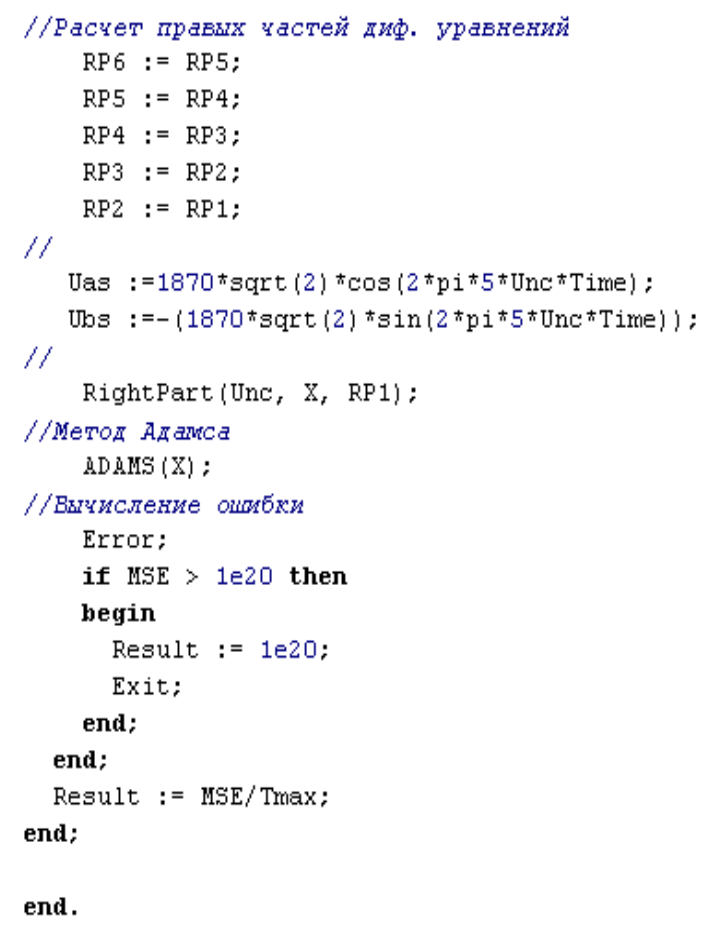

Даний блок реалізує розрахунок системи диференціальних та алгебраїчних рівнянь, що описують асинхронний двигун методом Адамса четвертого порядку.

Вказується кількість диференційних рівнянь у системі, а сама вона записується за формою Коші. Виконується розрахунок критерію якості перехідного процесу.

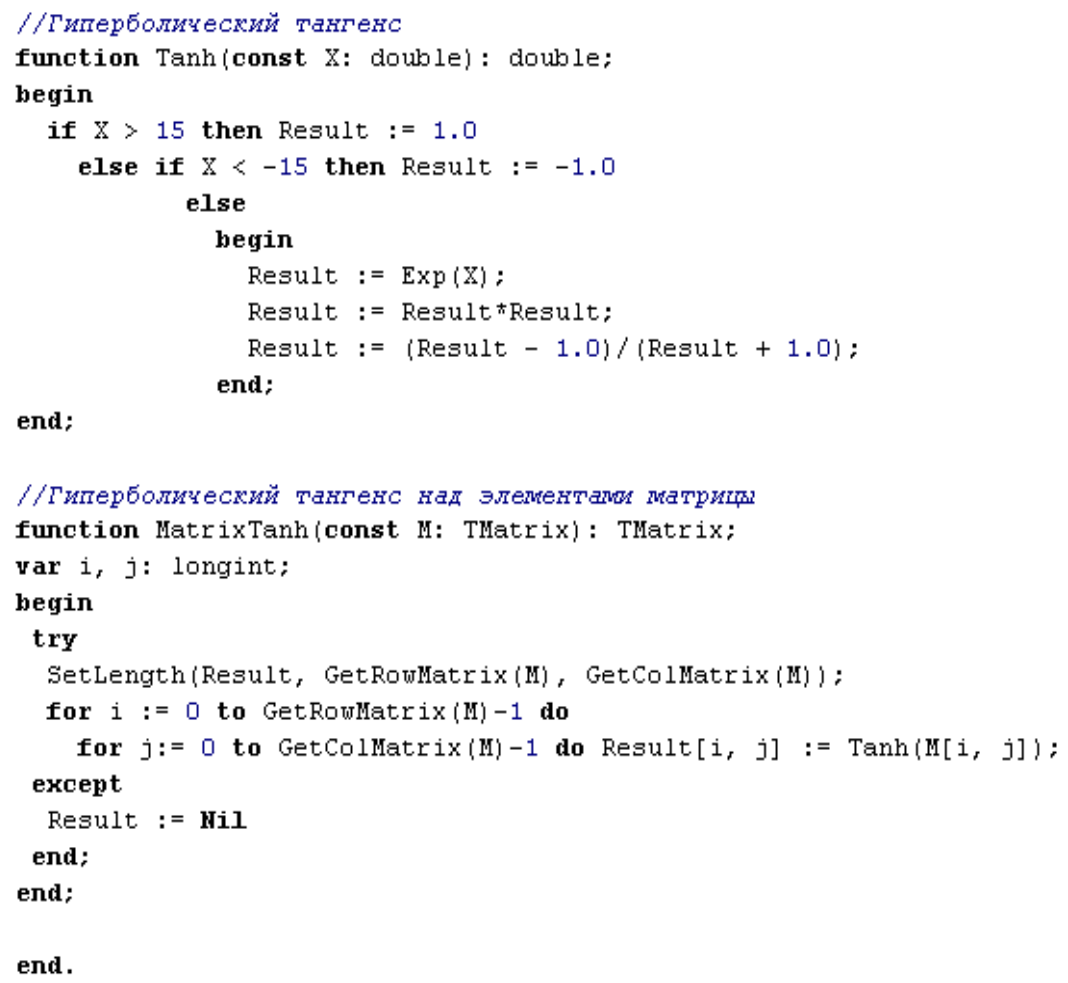


Цей блок оперує з матрицями вагових коефіцієнтів нейроконтролера.

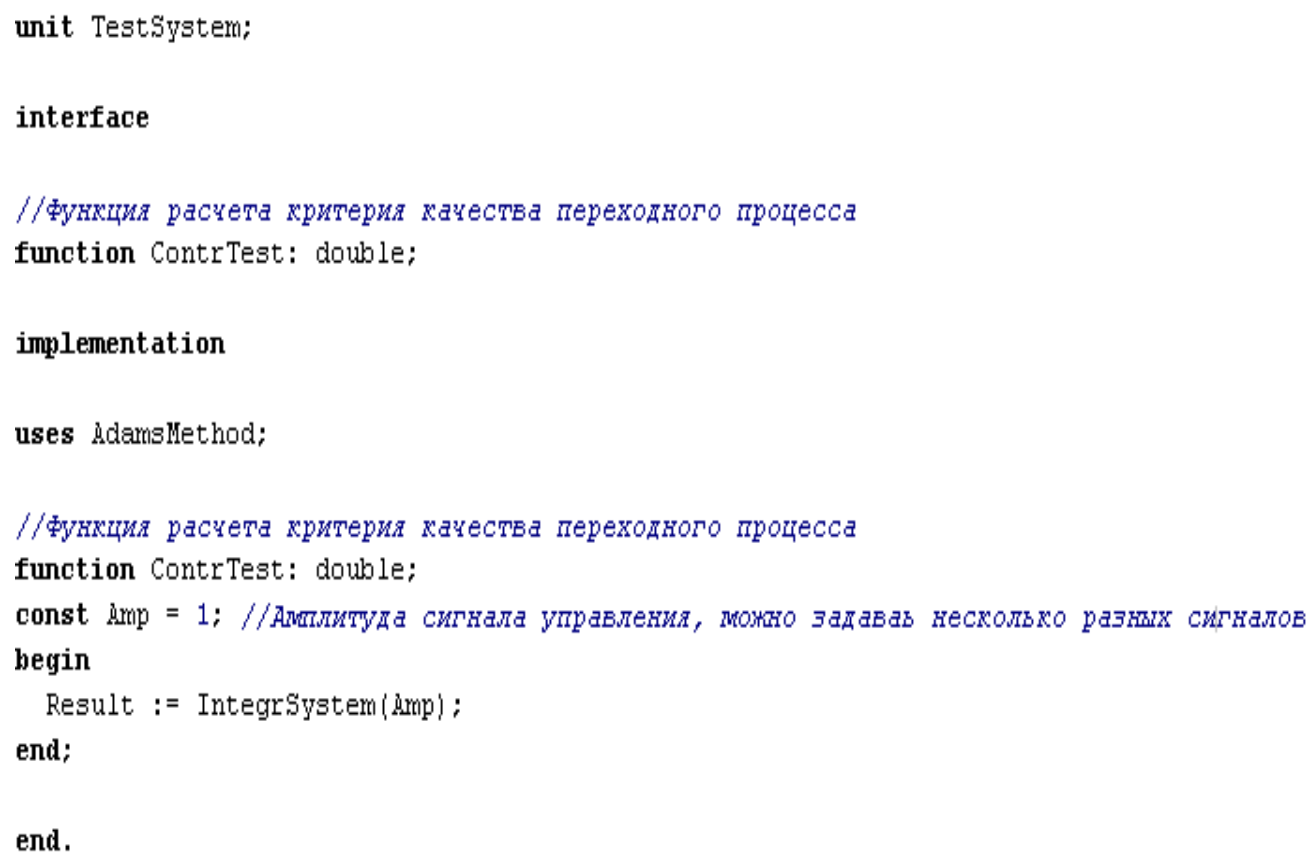

Блок «TestSystem» задає спосіб розрахунку перехідного процесу шляхом задання кількості сигналів керування. У фіналі при запуску програми отримуємо dll-бібліотеку lokomotiv.dll, що розміщується у попередньо створеному каталозі TASK.

Далі виконуємо такі дії:

Запускаємо Mendel i створюємо новий проект, вказавши в ньому як dll-файл бібліотеку lokomotiv.dll. Настроюємо параметри генетичного алгоритму: кількість особин - 10, вибираємо відсоток кросоверів, мутацій і т. д., запускаємо завдання. У секції [параметри] файла звіту містяться параметри нейроконтролера, синтезованого за допомогою Mendel. По цій секції створюємо файл для Matlab або текстовий, або двійковий (NC.mat). Для створення двійкового файла використовуємо програму RepToMfile.exe. Запускаємо Matlab 6.5 Simulink i відкриваємо в ньому файл AD914.mdl (модель для дослідження асинхронного двигуна). Запускаємо модель AD914.mdl на розрахунок, отримуємо перехідні процеси в системі з нейроконтролером.

Результати моделювання, наведені на рис. 2, 3, 5, 6, показують, що бажаний критерій оптимізації - скорочення часу перехідного процесу - досягнуто, проте оскільки для спрощення програми в модулі «TestSystem» амплітуда сигналу управління задана одним значенням (якість перехідного процесу), то величина пускового моменту не втримується в потрібних межах; незважаючи на це, результати можна визнати успішними, оскільки характер процесу збігається із потрібним. 


\section{Електричний транспорт}
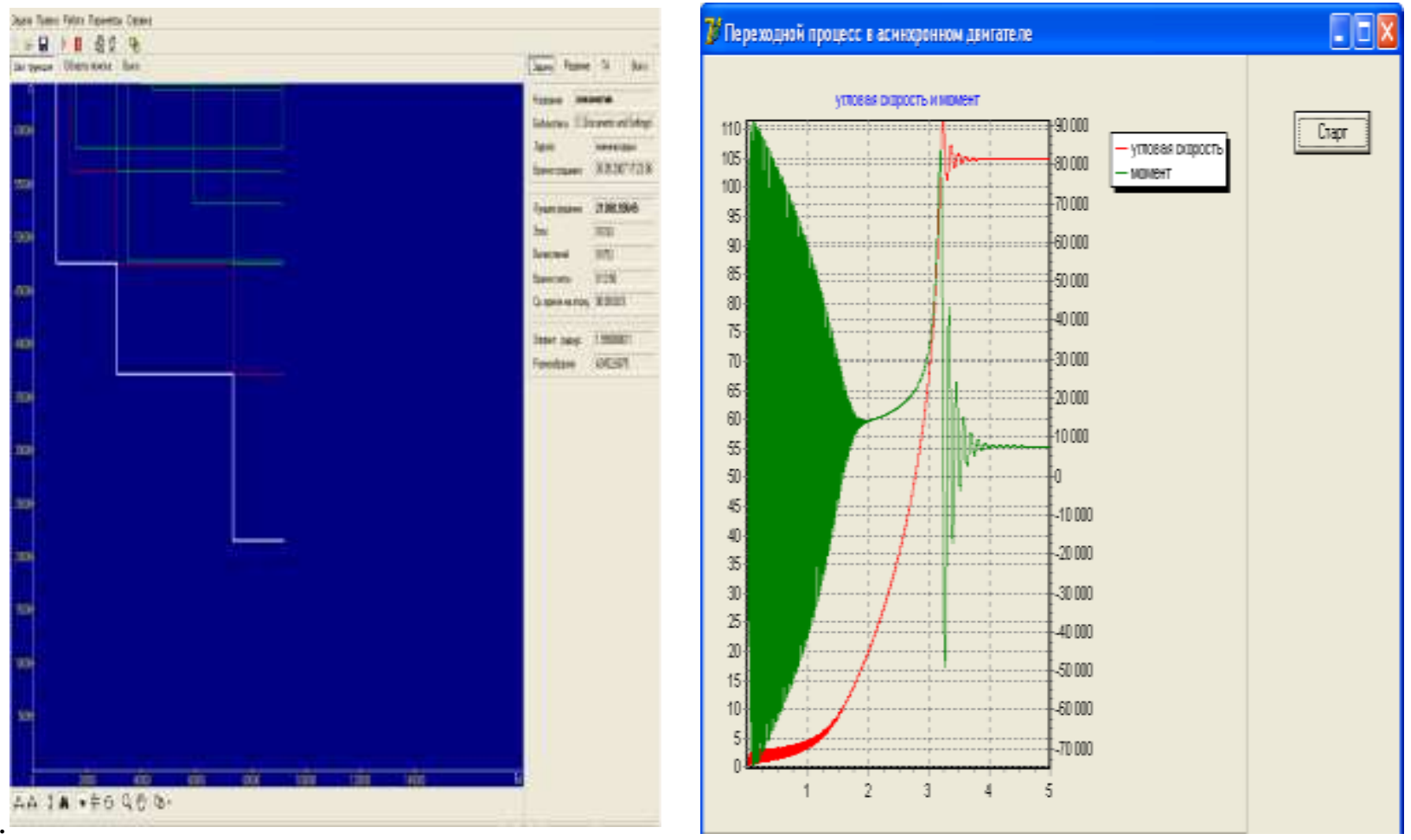

Рис. 2. Пошук параметрів нейроконтролера за допомогою Mendel 4

Рис. 3. Перехідні процеси в системі ПЧ-АД

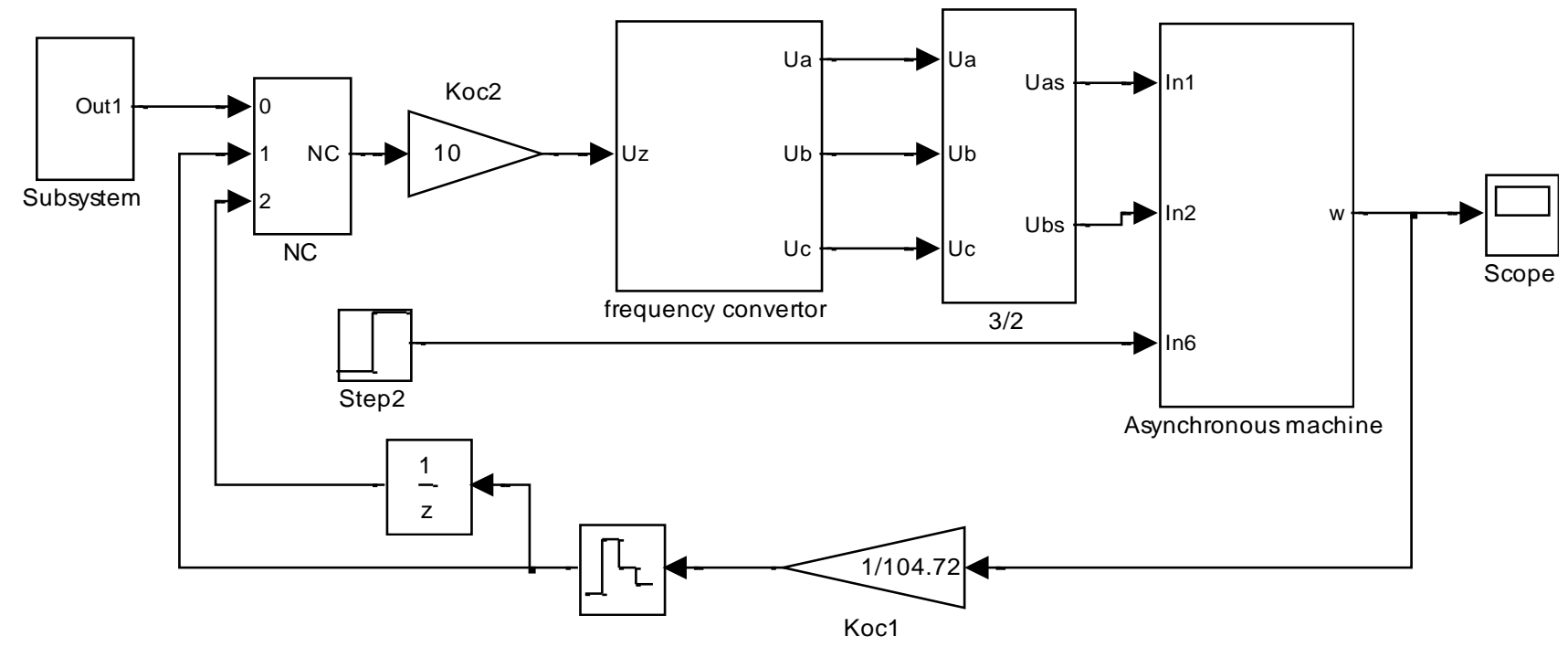

Рис. 4. Математична модель, на якій досліджувався нейроконтролер як елемент системи керування тяговим асинхронним електродвигуном 


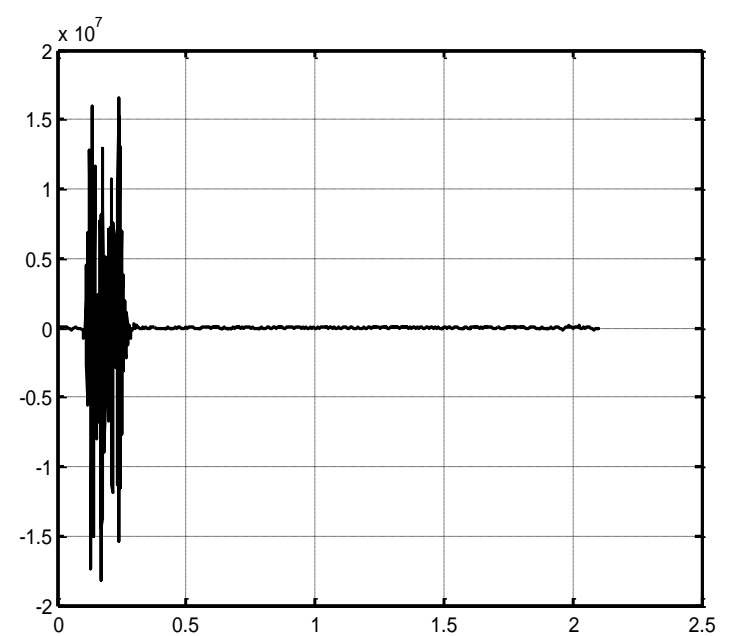

Рис. 5. Осцилограма моменту двигуна

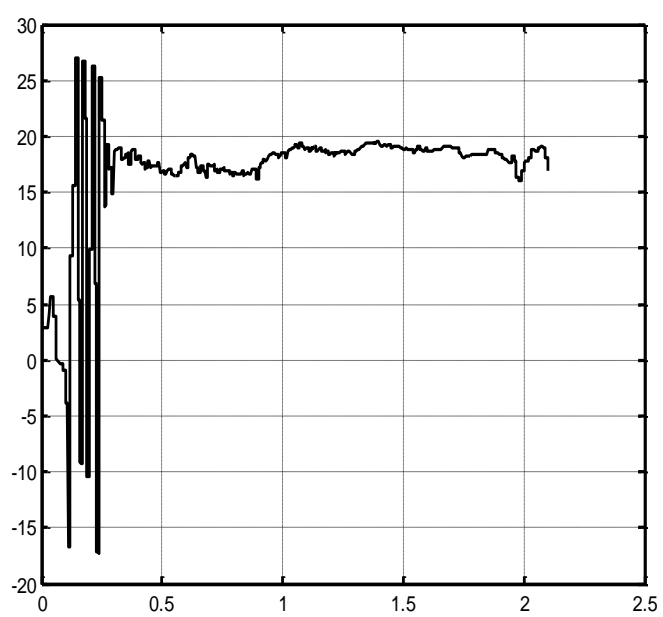

Рис. 6. Осцилограма закону керування

\section{Список використаних джерел}

1. Андреев, В.П. Основы электропривода [Текст]: учебник / В.П. Андреев, Ю.А. Сабинин. - М.: ГОСЭНЕРГОИЗДАТ, 1963. -772 с.

2. Бурков, А.Т. Электронная техника и преобразователи [Текст]: учеб. для ВУЗов ж.-д. трансп. / А.Т. Бурков. - М.: Транспорт, 1999. - 464 с.

3. Ключев, В.И. Теория електропривода [Текст] / В.И. Ключев. - М.: Енергоатомиздат, 1985. $-560 \mathrm{c}$.

4. Теория электрической тяги [Текст] / В.Е. Розенфельд, И.П. Исаев, Н.Н. Сидоров, М.И. Озеров; под ред. И.П. Исаева. - М.: Транспорт, 1995. - 294 с.

5. Чиликин, М.Г. Общий курс электропривода [Текст] / М.Г. Чиликин, А.С. Сандлер. М.: Энергоиздат, 1981. - 567 с.

Рецензент д-р техн. наук, професор А.П. Фалендиш

Павелко Дмитро Володимирович, слухач гр. МЗ-ЕТ-Б-11.

Буряковський Сергій Геннадійович, канд. техн. наук, доц. кафедри автоматизованих систем електричного транспорту.

Pavelko D.V., Buryakovskyy S.G. cand. of techn. sciences 